\title{
The Connection of Thought, Culture and Language: Revoking Myth Unveiling Truth
}

\author{
Khairuddin \\ Politeknik Kesehatan Kemenkes Malang
}

\begin{abstract}
Scholars and laymen alike are interested in understanding how thought, culture and language are related. Misunderstanding of this relatedness may have serious consequences: legislators make misleading constitutions, judges impose wrong legal rulings and imprisonment on the innocent, and educators apply ineffective pedagogy. Relativism and mentalism, the two leading linguistic schools of thought, have been around in sharp differences explaining about the relation between thought, culture and language. Relativism believes that language precedes, determines, and influence or shapes though, whereas mentalism hypothesizes the contrary that it is thought that creates and changes language. This article describes the theoretical concepts and empirical proofs underlying the two views of linguistic views. By using literature comparative analysis, this study has found that mentalism has strong standpoints in comparison with relativism's which have weak standpoints. This study also presents implications for language learning that are rooted in the mentalism conception.
\end{abstract}

Key Words: language, thought, culture, relativism, mentalism

\section{INTRODUCTION}

Pinker's (1994) words. "I have never met a person who is not interested in language," would suffice to describe people's interest in language, especially the connection of language, thought, and culture. Common people try to understand, make conclusion, and perhaps make personal arguments about them in a casual discussion among friends. Experts with scholarly arguments have presented serious literature about the connection with their own logic, empirical support and probing methods. Every reason for enquiring the connection between language, thought and culture is validly important since not knowing or misunderstanding of it might lead to serious misleading consequence, such as what had happened to Robert Meyer (Stenberg at. al. 2000), a German-origin American teacher in 1920, who was arrested and sentenced to imprisonment because his teaching German language to a 10-year old American boy was considered violating a certain state law of Nevada (also in 21 other states) which forbade the teaching of a foreign language other than English to children under the age of 13 years. The language was believed to have shaped the German culture who has created leaders such as Adolf Hitler, perpetrator of the World War 1 horror, and so to teach such a language to young Americans would be immoral and corrupting. Only after psycholinguistic consideration and justification (that "mere knowledge of the German language cannot reasonably be regarded as harmful; Knowing a foreign language would not in itself provide the values and culture of the country from which that language is derived) was entertained in the US Supreme Court appeal did he win the case and was released. The present article discusses several theories regarding the relationship of language, thought and culture available in the relevant literature though not comprehensively. The discussion begins with the less promising because of their inadequacy of research methods, incomprehensive empirical data, and erroneous beliefs underlying their theorizing, to the more recent and promising theories with stronger research tradition, with their superficial implication in language learning enterprise. The article is not only meant for mere interesting knowledge sake, but it is also hoped to equip its readers with anticipation of mankind language-related behavior in all sizes and kinds of living and interacting societies. 


\section{Weak Theories Regarding the Dependence of Thought and Culture on Language}

The first weak theory is that speech is essential for thought; we must learn how to speak, otherwise we cannot develop thinking (Watson, 1924; Skinner, 1957; Bloomfield, 1961). The proponents hold the view that thought is a kind of behavior, speech, which originates from speech production. It develops as a kind of speech: from speaking aloud, you start to speak subvocally or make internal articulations. Thus, thought is defined as subvocal speech or behavior and not something mental. The first objection is that children having no speech production can comprehend speech and think. The absence of the ability to produce speech may not indicate a lack of language knowledge. People born with cerebral palsy or some other abnormality that have caused them to be born mute (not losing hearing ability) and never able to speak but they can learn to read words, with understanding, that she could not say. None of these persons could speak. If a person can comprehend the meaning of speech, that person must have the ability to think. Thus, we can conclude that persons without the ability to speak can think. The notion that speech production is necessary in order to think is clearly false. In Indonesian setting this false notion is also displayed on a daily basis in Indonesian TV soap operas or sinetron when the characters frequently are creating inner speech in their thinking prior to taking an action, such as before an antagonist character is about to do harm to the protagonist one). Secondly, in language developmental process, speech comprehension precedes speech production. Children aged 10 to 13 months are able to comprehend speech at a level beyond that to which they had progressed in production (Hutten Locher in Stenberg at al 2000). In addition, children who can only produce single-word utterances nevertheless could understand syntactic structures composed of more than one word. A 2-year old boy can be taught to read (understand the meaning of) many written words, phrases and sentences before he is able to say them. Thus, for normal children as well as for mute hearing children, speech comprehension is the basis for speech production in the mind. Since the ability to comprehend speech implies the existence of thought, it therefore must be concluded that speech production is not necessary for thought.

The second weak theory is that language is essential for thought; we must learn language, how to produce and understand speech, otherwise we cannot develop thinking. The proponents of this hold the view that the language system, with its rules for vocabulary, is necessary for thought, both for speech production and speech understanding. Sapir (1921), the forefront proponent of this theory, claims that " the opinion that the feeling entertained by so many that they can think, or even reason, without language is an illusion" ( $p$. 15), which is accorded by Whorf (1956). The theory raises serious objection. Deaf people from birth who have no language can think. Children who have congenital hearing loss and are unable to receive speech can participate in play or other activities around the home and behave just as intelligently and rationally with respect to their environment as do hearing children. If one holds that language is the basis for thought, one would have to argue that these children do not think; that they were automatons, mere robots. Further, if one holds that grammar determines how we dissect nature, than it must be argued that either the nonlanguage deaf children cannot dissect nature or, if they do, they do so differently from children who do have grammars. However, there is no difference in intelligence between normal and deaf persons, eventhough the language knowledge of the deaf persons far below that of hearing persons (Furth 1971). In addition, Helen Keller, living no language input from when she was 19 months of age until she was about 7 years old, actually reported in her book The Story of My Life many memories of the period in which she was without language. If she was unable to think during her life without language she would not be able to think and store it in her memory for recalling. Another case, an American deaf man (Schaleer in Stenberg at al 2000), who after he acquired sign language at age 27 years, was able to describe experiences in 
his previous non-language life in sign language. The man was a thinking human being even before he acquired human language. Such a thought cannot be explained by the theory that thought comes to existence through language.

The third weak theory is that language determines or shapes our perceptions of nature; the learning of language will determine or influence the way we perceive the physical world. The proponents of this theory, Whorf, Sapir and others hold that one's knowledge of vocabulary or syntax influences one's perception and understanding of nature. The first objection claims the converse should be true, that perception, interest, and need determine vocabulary, not vice versa. It is our interest and need that determine our coinage of vocabulary and its use. Nowadays people know little of the vocabulary surrounding horses and horsedriven transportation. We know a lot, though, about automobiles and their parts and functions. Any teenager can give you 25 or more words for car and motorbike models. Vocabulary is selected for use. Once it fails to serve a need, it falls out of use (Westen 1996). Second objection is related to color, pronoun, snow/rice and time vocabulary. Brown and Lantz (in Stenberg at al 2000) suggest that knowing words does not influence perception of the world. Regarding colors, Dani language of New Guinea has only two color words, one for light colors and one for dark colors. But with such a limited repertoire of color terms, they don't have perceptual difficulty in distinguishing colors they have no terms for (Stenberg at al 2000). Thus, speakers of different languages which have only two, three, or four color terms are as capable of distinguishing among the many color bands of the visible spectrum as those whose languages have more than eight basic color terms. After all, the average human being is able to distinguish some seven million different colors on the spectrum; yet in most languages, there is only a handful of color words in common use (Cooper 1979). People can see differences but just will not give them a name unless there is a good reason to do so. Thus we can conclude, rather than language determining perception, it is perception that determines language. In terms of the presence or absence of certain pronouns in a language, we can look at the Indonesian context. The linguistic fact that there is no third person singular in Madurese, does it change or influence Madurese people's thought? Or is it because Madurese people do not recognize the concept of third person singular therefore they don't have linguistic feature for that pronoun case? Does it mean that they can't see or understand the differences between third person singular and third person plural? To compare, English language does not have different pronoun words to indicate between second person singular "and second person plural, either. English use "you" for both. Does it mean that English people do not recognize the different concepts of second person plural or second person singular? Which concept do they have in mind when they use the word "you"? The answer is, ofcourse, English people understand and recognize the different concepts between second person singular and plural although they only have one signifier "you" for the two concepts ( so are the Madurese people with their third person singular case). The two sentences "you are $a$ star" and "you are students" are proofs that they understand and recognize second person singular and plural. In conclusion, vocabulary does not determine our knowledge/awareness of relational concepts; it is our need and interest that determine our coinage of vocabulary and its use. Regarding snow words, Inuit have a large number of words involving snow. In Hawaii, there is only one word 'snow'. However, there is no reason to suppose, though, that Inuit learn to perceive verities of snow because of their language rather than through their life experience and needs. It is because of the importance of snow in their lives that they have created more words for snow than have Hawaiian (Stenberg at al 2000). The same thing is true to Hanonoo of the Philippines and their 92 words for rice (Westen 1996). Concerning Hopi time concept, the Whorfians believe the fact that Hoppi language have few words relating to time, they have radically different concept of space and time from speakers of European languages, for example. Claiming 
the Hopi language is timeless one is a wrong call (Gipper in Stenberg at al 2000). Although Hopi does not have a formal tense, it nevertheless contains a whole series of expression for time. Many of these expressions appear as adverbs or prepositions. In addition, Hopi also do use a variety of time referents such as periods relating to harvest, the moon, the sun, and other significant events. English people do much the same in their language (Let's go when it gets dark, or I'll fix it when the weather gets warm). The conclusion is that people are not different because of their languages, but because of their experience.

The fourth weak theory is that language determines or shapes our world view. The learning of language will determine or influence the way we understand our culture and the world. The proponents of theory 4 (Sapir and Korzybsky in Stenberg at al 2000) believe that even if language is somewhat distinct from thought, nevertheless, knowing a language will itself condition and influence one's cultural, social beliefs or views of the world. If these theories are correct, we would expect to find differences and similarities in such essentials as philosophy, religion, politics, or societal structures to be a function of language. There also some objections to these contentions (Stenberg at al 2000). First, there are people with the same language but yet different world views. Consider for example the United States, where we can find monolingual native speakers of the same English language who vary greatly in terms of their philosophical, religious, and political ideology. Variation may be observed among speakers in the same neighborhood and even in the same family. Consider for example, a monolingual English speaking family where the mother is an atheist, the father a Christian, the daughter a Moslem, and the son a Zen Buddhist. If it is true that language influences or determines one's world view, then we should expect uniformity of religious outlook since only one language system is involved, English. This is obviously false. Secondly, we would commonly find people who have or speak different languages and yet they have similar world views. We find for example that Buddhist, Christian, Communist, capitalist, authoritarian, democratic, militaristic, and vegetarian doctrines are shared by speakers of many very different languages. Thirdly, we find people with the same language but their world view change over time. We may observe that a society may change its social structure and world view even though its language remains relatively unchanged.

\section{Some erroneous beliefs underlying the weak theories}

According to Stenberg at al. (2000), there are three mistaken beliefs that have led the previous theorist to invalid conclusion. The first erroneous belief, the most serious deficiency in their theorizing (Whorf, Sapir, Humbold's), is that their analysis of language is adequate when in fact it is not. They assumed that the directly observable words or the structure of a sentence represent all of the semantic or thought elements of that pattern. They drew conclusion largely based on what linguists today would consider a superficial surface structure analysis. In fact, as Chomsky suggests (Stenberg at al. 2000)., that surface structure often does not directly exhibit basic relations and meanings. Moreover, they did not bother to seek out hard evidence to support their contentions In addition, those linguists had a tendency to focus on the differences between languages. Their guilt was also in their method problem (focusing on the differences between languages) which have led them to over translation because they translate overliterally (Cooper 1979). The second erroneous belief is their assumption that meaning of words is linguistic in origin, when in fact it is mere conventional. They are wrong to assume that the mere hearing of the sound form of a word (an unknown one) itself provides some sort of meaning. They do not allow for a prior mental experience because that would imply that thought precedes language. A language sound from itself, however, does not provide meaning. The third erroneous belief is their assumption there was such a thing as primitive people and that those people had a primitive grammar, and that this primitive grammar of these people reflected their 
thought, so they concluded that their thought was primitive too. Such notions about primitive peoples and primitive languages were virtually taken for granted in the first half of the twentieth century when Sapir and Whorf were doing their theorizing. Modern linguistic research has never found a single language that could be called primitive. It is Chomsky that can with some assurance assert that all languages are of similar complexity, with each having similar basic forms and operations (Stenberg at al 2000).

\section{The best theories of the connections between thought, culture and language}

The best theory 1 is that thought is independent of language, that language is dependent on thought, and that the function of language is to provide a means for the expression and communication of thought, as advocated by John Locke (Stenberg at al 2000). Part of the language system is actually part of the thought system, for the meaning and semantics of the language system are those ideas that are part of the content of thought. Thought and language systems are joined through meaning and ideas (Stenberg at al 2000). The next important proposition is that the development of thought precedes the development of language. As thought develops, children seek to express those thoughts to others. Through speech understanding children develop a grammar and find a means through speech production to provide meaningful speech. The grammar develops as the result of prior thought, thus the sequence is: thought to speech understanding to speech production. Another important proposition is that the notion of thinking in language is a fallacy. Although sound forms of words come to one's awareness while one is thinking, it is a mistake to conclude from this that the sound forms themselves are thought. Such word forms are merely reflections of some underlying ideas. It is thought which determines the selection of word forms. The sound form is not thought itself but simply a reflection of thought.

The best theory 2 is that language can assist in conveying new ideas and culture (Stenberg at al. 2000). Language may be used to provide new ideas. Novel ideas or thought may be conveyed by a sentence such as 'Every July 4, Mao drank Coke and sang the Star Spangled Banner'. It is important to note that it is not the component ideas and relations which are new but their unique arrangement. The structure and vocabulary are already known. Thus, novel sentences are created and understood on the basis of what a speaker already knows about the language in terms of its syntax and vocabulary. And if new words are to be introduced, they are explained in terms of old ones.

The best theory 3 is that language may be used to change beliefs and values. As a result of reading the Communist manifesto, say, one's values, beliefs, and world view could be radically changed. People who are so changed politically, religiously, etc., are often said to think differently. However it should be recognized that what really occurred were changes in the truth and attractiveness of the values which are assigned to propositions. A muallaf or convert to Islam, for example, does not change his faith because he has learned Arabic and that the Arabic language has changed him to a new faith. Rather, it's his willingness to accept the new truth and replace the old truth, not the language does the magic.

\section{CONCLUSION AND SUGGESTION}

As the final say, the article emphasizes the goal of this article which is, rather than to just getting mere interesting knowledge, the very reason and motivation to writing this article is to have a good understanding and be aware of the importance of the good understanding of the connection between language, thought and culture. This good understanding and awareness of their connection would give us sound ideas on how we humans should attempt in our behavior as an individual, as member of a family, as member of a society, as citizen of a nation, and even of the world. Wrong or misunderstanding of language, thought and culture relationship may lead to unjust and wrong course of action and reaction of the person to his/her immediate experience and environment. As a students' language teacher there is an implication of the importance of focusing more our 
instruction on thought provoking activities if we want to fix or develop our students' linguistic behavior. We could not just impose on our students' impersonal and nonfunctional activities such as memorizing and practicing linguistic features. Their linguistic behavioral change should be the result of their increased knowledge and understanding of the world which would bring about their change of thoughts and behavior in turn. We English teachers should provide our students with more chances for them to construct knowledge for themselves and less on transferring knowledge onto them. The teachers' main concern should be to help students develop their tacit knowledge of L2 (L2 competence) as the basis for their L2 performance development.

\section{REFERENCES:}

Bloomfield, Leonard. 1961. Language. London: Allen \& Ulwin

Cooper, David. (1979). Philosophy and the Nature of Language. England: Longman.

Furth, H. G., \& Youniss, J. (1971). Formal operations and language: A comparison of deaf and hearing adolescents. International Journal of Psychology, 6(1), 49-64.

Pinker, Steven. (1994). The Language Instinct: The New Science of Language and Mind. London: Penguin Books.

Sapir, Edward. (1921). Language: An Introduction to the Study of Speech. New York: Harcourt, Brace.

Skinner, B. F. (1957). Verbal behavior. New York: Appleton-Century-Crofts.

Stenberg, D., Nagata, H., Aline, D. (2001). Psycholinguistics: Language, Mind and World. Harlow: Longman.
Watson, J. B. (1924). The Place of Kinaesthetic, Visceral and Laryngeal Organization in Thinking. Psychological Review, 31(5), 339-347.

Westen, Drew. (1996). Psychology: Mind, Brain and Culture. New York: John Wiley \& Sons.

Whorf, B.L. (1956). Language, Thought and Reality. Selected Writings. Ed.: J.B. Carroll. MIT, New York: J.Wilky/London: Chapinaon \& Hall. 